\title{
Efficacy of Probiotic, Chlorhexidine, and Sodium Fluoride Mouthrinses on Mutans Streptococci in 8- to 12-Year-Old Children: A Crossover Randomized Trial
}

\author{
Krutika Y. Gedam Amar N. Katre \\ Department of Pediatric and Preventive Dentistry, YMT Dental College and Hospital, Navi Mumbai, India
}

\section{Keywords}

Bacteriotherapy · Children · Mouthrinse · Mutans

streptococci $\cdot$ Prevention $\cdot$ Probiotics

\begin{abstract}
Introduction: The oral cavity is home to a diverse and distinct microbiome. While the role of oral bacteria in cariogenic and other dental diseases is irrefutable, their beneficial effects in the form of probiotics (PB) has been less studied, especially pertaining to oral diseases in children. This study compares the efficacy of a PB mouthrinse with $0.12 \%$ chlorhexidine (CHX) and $0.05 \%$ sodium fluoride (NaF) mouthrinse on the colony counts of mutans streptococci (MS) in children. Methods: A triple-blind crossover randomized trial between interventional groups was planned. Fifty-one children between 8 to 12 years of age were divided into three groups (I, II, and III) and were exposed to all three mouthrinses $(A, B$, and $C$ ) by randomized allocation for a period of two weeks with an inter-phase washout period of four weeks. Pre- and post-interventional MS counts (CFU/mL) were assessed, and the mean change was analysed using the $t$ test (intragroup) and ANOVA (intergroup and crossover). Results: The mean changes in the colony counts obtained with the use of $\mathrm{PB}, \mathrm{CHX}$, and $\mathrm{NaF}$ mouthrinses were -1.0223
\end{abstract}

karger@karger.com www.karger.com/lfg

Karger"

BOPEN ACCESS
(C) 2022 The Author(s)

Published by S. Karger AG, Basel

This is an Open Access article licensed under the Creative Commons Attribution-NonCommercial-4.0 International License (CC BY-NC) (http://www.karger.com/Services/OpenAccessLicense), applicable to the online version of the article only. Usage and distribution for commercial purposes requires written permission.
$(-1.2201$ to -0.8246$),-0.9564(-1.1503$ to -0.7626$)$, and -0.9511 ( -1.1554 to -0.7467$)$, respectively, which were statistically significant $(p<0.0001)$. However, the intergroup comparison for the mean change in colony counts revealed no statistically significant differences $(p>0.05)$. Conclusion: The study concluded that the PB mouthrinse was equally efficacious as compared to $\mathrm{CHX}$ and $\mathrm{NaF}$ mouthrinses against MS in 8- to 12-year-old children. However, further studies are recommended to strengthen the evidence.

(c) 2022 The Author(s).

Published by S. Karger AG, Basel

\section{Introduction}

Microbiome research has become central to disease pathogenesis and that of the oral cavity holds significance in the aetiology for many oral and systemic diseases. With over 700 bacterial taxa, the oral microbiome is extremely dynamic and maintains equilibrium despite its "continuum with the external environment" [1].

Dysbiotic states driven by ecological stress in the oral biofilm convert commensal bacteria to opportunistic, which lead to pathogenesis. Dental caries is the result of dysbiotic changes in the ecology of the oral biofilm [2]. Early cultivation studies and animal experiments isolated 
Streptococcus mutans (S. mutans) from carious lesions [3, 4] and identified it as the principal bacteria responsible for dental caries in humans. S. mutans is highly acid-tolerant, creates impenetrable biofilms, and is genetically evolved to withstand oral environmental changes, which safeguards its cariogenic potential [2].

Recently, the prevalence of dental caries has increased in developing countries, due to high refined sugar consumption, inadequate fluoride exposure, high oral health service costs, etc. [5]. In India, 51.9\% of 5-year-old, 53.8\% of 12 -year-old, and $63.1 \%$ of 15 -year-old children are affected by dental caries [6].

Long-term prevention of dental caries can be implemented by interfering with deleterious factors that shift the microbial equilibrium [7], and regular tooth brushing is one means to achieve it. Regular tooth brushing prevents the accumulation of cariogenic biofilm; however, in children, factors such as lack of dexterity, individual motivation, and monitoring can limit its effectiveness [8]. Therefore, adjunctive use of chemotherapeutic agents in the form of mouthrinses is recommended $[9,10]$. The chlorhexidine (CHX) mouthrinse, due to its proven efficacy, has been established as the "gold standard" or positive control for comparison with other agents [11]. Fluoride, since its inception through water fluoridation, is widely accepted as a caries-preventive regimen [12].

"Bacteriotherapy," an alternative approach that works on the principle of harmonizing oral ecology and reducing the number of cariogenic bacteria, is of special interest [1]. Probiotics (PB) are being researched as a contender for bacteriotherapy. PB are defined as, "live microorganisms that, when administered in adequate amounts, confer a health benefit on the host" [13]. PB bacteria replenish the diversity of a dysbiotic microbiota [14]. Their mechanism of action on the oral biofilm is debatable; nonetheless, several theories postulate that PB bacteria secrete antimicrobial substances like bacteriocins, hydrogen peroxide, and organic acids, whilst against pathogenic microbes, they compete for nutrition, growth factors, and adhesion sites. Additionally, they can also stimulate non-specific immunity and improve the cellular and humoral response [15].

$\mathrm{PB}$, administered in different forms, have previously been studied to determine their effectiveness against cariogenic oral microbiota [15-18]. A crossover study in adults assessing Kefir PB drink against sodium fluoride $(\mathrm{NaF})$ has reported significantly lower levels of salivary mutans streptococci (MS) [18]. Furthermore, a parallel group study comparing the efficacy of $\mathrm{CHX}, \mathrm{NaF}$, and $\mathrm{PB}$ powder as mouthrinses in adults found that the PB pow- der reduced plaque $S$. mutans levels, without any untoward harmful effects [19]. As of yet, no crossover randomized trial has reportedly been performed in children with the three mouthrinses. Therefore, the purpose of this trial was to compare the efficacy of $\mathrm{PB}, \mathrm{CHX}$, and $\mathrm{NaF}$ mouthrinses on MS in children of 8-12 years of age. We also assessed the modifying effect of age, sex, and crossover; the patient's acceptance to taste; and their compliance.

\section{Methods}

The CONSORT checklist was used in conducting and reporting this three-group, crossover randomized trial with an allocation ratio of $1: 1: 1$.

\section{Settings, Location, and Participants}

The study was designed and carried out in the Department of Pediatric and Preventive Dentistry, YMT Dental College and Hospital, Navi Mumbai, India. One hundred and seventeen healthy children were screened for eligibility, of which, 51 children between 8 to 12 years of age with a total caries score $(\mathrm{dmft}+\mathrm{DMFT})$ (d/D: decayed, $\mathrm{m} / \mathrm{M}$ : missing, and f/F: filled teeth) (primary + permanent dentition) between four and ten were selected. Children with recent $\mathrm{H} / \mathrm{o}$ antibiotics, undergoing orthodontic treatment, with I/o soft tissue pathology, in whom saliva collection was not possible owing to disability or who could not rinse on their own were excluded.

\section{Intervention}

Demographic details and baseline total caries score $(\mathrm{dmft}+$ DMFT) of the participants were recorded by the primary investigator before commencement of the trial. The participants were randomly divided into three groups namely group I, group II, and group III using a computer-generated sequence. Participants in each group received all three mouthrinses, each coded as A, B, and C by randomized allocation, performed by an independent observer.

Each intervention phase spanned two weeks. Parents were instructed to measure $10 \mathrm{~mL}$ of $\mathrm{CHX}$ and $\mathrm{NaF}$ mouthrinses in a plastic calibrated measuring cup, and the participants were advised to rinse it for one minute, swish, and spit, twice a day, after tooth brushing under parental supervision. PB powder sachets were opened and freshly prepared by parents, by mixing the powder in $10 \mathrm{~mL}$ of water and using the solution as a mouthrinse. Participants were asked to refrain from eating, drinking, or brushing for at least one hour after rinsing. Before each new phase, along with the new mouthrinse, participants were provided with a customized pre-marked calendar that highlighted the number of times and days of use. They were instructed to fill it simultaneously while using the mouthrinse. The second and the third interventional phases were carried out in a similar manner with a washout period of four weeks. Throughout the trial, participants were to follow their regular diet and oral hygiene practices using a non-fluoridated toothpaste.

\section{Saliva Collection and Bacterial Culturing}

One millilitre of paraffin-stimulated mid-morning [20] saliva samples were collected by the primary investigator from all participants in duly labelled sterile Eppendorf tubes at baseline and at the end of each
Gedam/Katre 
phase. All the tubes were labelled by an independent investigator to ensure blinding of the primary investigator, immediately sealed, coded, and sent for culturing. Corresponding patient codes were also labelled onto the mitis salivarius-bacitracin (MSB) agar petri dishes for an accurate bacterial count record of respective participants.

MSB agar was prepared with addition of $1 \%$ potassium tellurite. The samples were streaked onto MSB agar plates and incubated in a $5 \%$ carbon dioxide incubator at $37^{\circ} \mathrm{C}$ for $48 \mathrm{~h}$ and examined for growth of MS. The colonies were identified by their morphology, i.e., raised, convex, undulate, opaque, pale-blue colonies with "frosted glass" or granular appearance on the agar surface. Colony counting was done with the help of a colony-counting meter as $\mathrm{CFU} / \mathrm{mL}$ at the end of $48 \mathrm{~h}$. The dilution factor used was $10^{5}$.

\section{Outcomes}

The primary outcome variable assessed was the colony counts of MS (CFU/mL) after the use of the mouthrinses. We also assessed the effect of crossover and the effect of modifier variables viz. age and sex.

The secondary outcome variables assessed were the taste acceptance and the compliance to use of the three mouthrinses. The taste acceptance was recorded on a 5-point Likert rating scale (ranging from 1: very bad, 2: bad, 3: okay, 4: good, and 5: very good), by the primary investigator. As for the compliance, participants submitted the filled calendars to the primary investigator after each phase. Both outcomes were reviewed when participants reported for post-intervention saliva collection, immediately after each phase. Adverse effects, in the form of gastrointestinal dysfunction, taste disturbance, tooth staining, or any other symptoms, were also noted.

\section{Sample Size Estimation}

Considering that the proposed study was a three-group, crossover, randomized trial with $\alpha$ at 0.05 and $\beta$ at $<0.2$ (power at $80 \%$ ) with an assumed non-inferiority margin [19] at 0.6163 , a sample size of 42 participants would be required. Assuming a dropout rate of $20 \%$, a total of 51 participants were enrolled in the study.

\section{Randomization and Blinding}

Each participant was coded with numbers $01-51$. Mouthrinses were coded as A, B, and C and dispensed to the participants according to the computerized sequence. An independent observer dispensed the pre-measured quantity of mouthrinses to the allocated participant, in white opaque bottles to mask the content before each phase began. The primary investigator collected the saliva samples at the start and end of each phase and hence was blinded and unaware of the type of the mouthrinse dispensed. The statistician was blinded to the coding of all the three interventions.

\section{Statistical Analysis}

The data were captured into a Microsoft Office Excel (version 2013) spreadsheet. Data analysis was done using Windows-based MedCalc statistical software version 13.3.1 (MedCalc Software bvba, Ostend, Belgium; http://www.medcalc.org; 2014).

The change in the colony counts of MS was expressed as the mean change and mean percentage change with standard deviation. The effect of crossover was expressed as the estimated marginal means and estimated marginal mean percentages. The patient acceptance to taste was expressed as ranked proportions. The patient compliance was recorded as a binary categorical variable and expressed as proportions.

Efficacy of a Probiotic Mouthrinse on Mutans Streptococci
Table 1. Distribution of study population (age and sex-wise)

\begin{tabular}{lllllll}
\hline $\begin{array}{l}\text { Participants } \\
(n=51)\end{array}$ & 8 years & 9 years & 10 years & 11 years & 12 years & Total \\
\hline Boys (26), \% & 15.7 & 13.7 & 7.9 & 1.9 & 11.8 & 51 \\
Girls (25), \% & 13.7 & 13.7 & 7.9 & 5.8 & 7.9 & 49 \\
\hline Total, \% & 29.4 & 27.4 & 15.8 & 7.7 & 19.7 & 100 \\
\hline
\end{tabular}

An intent-to-treat (ITT) analysis was performed to account for the attrition in sample. A per protocol (PP) analysis was performed on participants who completed all three phases. Intragroup comparison was analysed using the paired-sample $t$ test to assess the change in $\mathrm{CFU} / \mathrm{mL}$ with the three interventions. Intergroup comparison and the effect of crossover on the mean change and mean percentage change in colony counts of MS were analysed using ANOVA. The $\chi^{2}$ test was used to assess taste and compliance. Analysis of covariance (ANCOVA) was applied to assess the effect of age and sex in addition to crossover on the primary outcome. Spearman's coefficient of rank correlation was used to assess the correlation between acceptance to taste and compliance. $p<0.05$ was considered significant.

\section{Results}

The study population comprised of 51 children of which 26 (50.98\%) were boys and 25 (49.02\%) were girls, the mean age being $9.6 \pm 0.4$ years (Table 1). Of the 51 participants, 19 completed all the three phases of the study (Fig. 1). The recruitment period for the trial extended from January 2017 to February 2017. The trial was completed by June 2017.

\section{Primary Outcomes}

A significant reduction in the colony count of MS was observed with use of the individual mouthrinses $(p<$ 0.0001 ) (Table 2). Intergroup comparison using ITT and $\mathrm{PP}$ analysis revealed no significant difference in the reduction of colony counts of MS between the three mouthrinses $(p>0.05)$ (Table 3). Intergroup comparison with the crossover effect revealed no significant difference in the estimated marginal means and estimated marginal mean percentages of MS $(p>0.05)$ (Table 4).

\section{Secondary Outcomes}

\section{Taste and Compliance}

Most participants rated the taste as "good" $\left(\chi^{2}=9.189\right.$, $p>0.05$ ) with no significant difference between the three mouthrinses. The overall compliance, across the three 


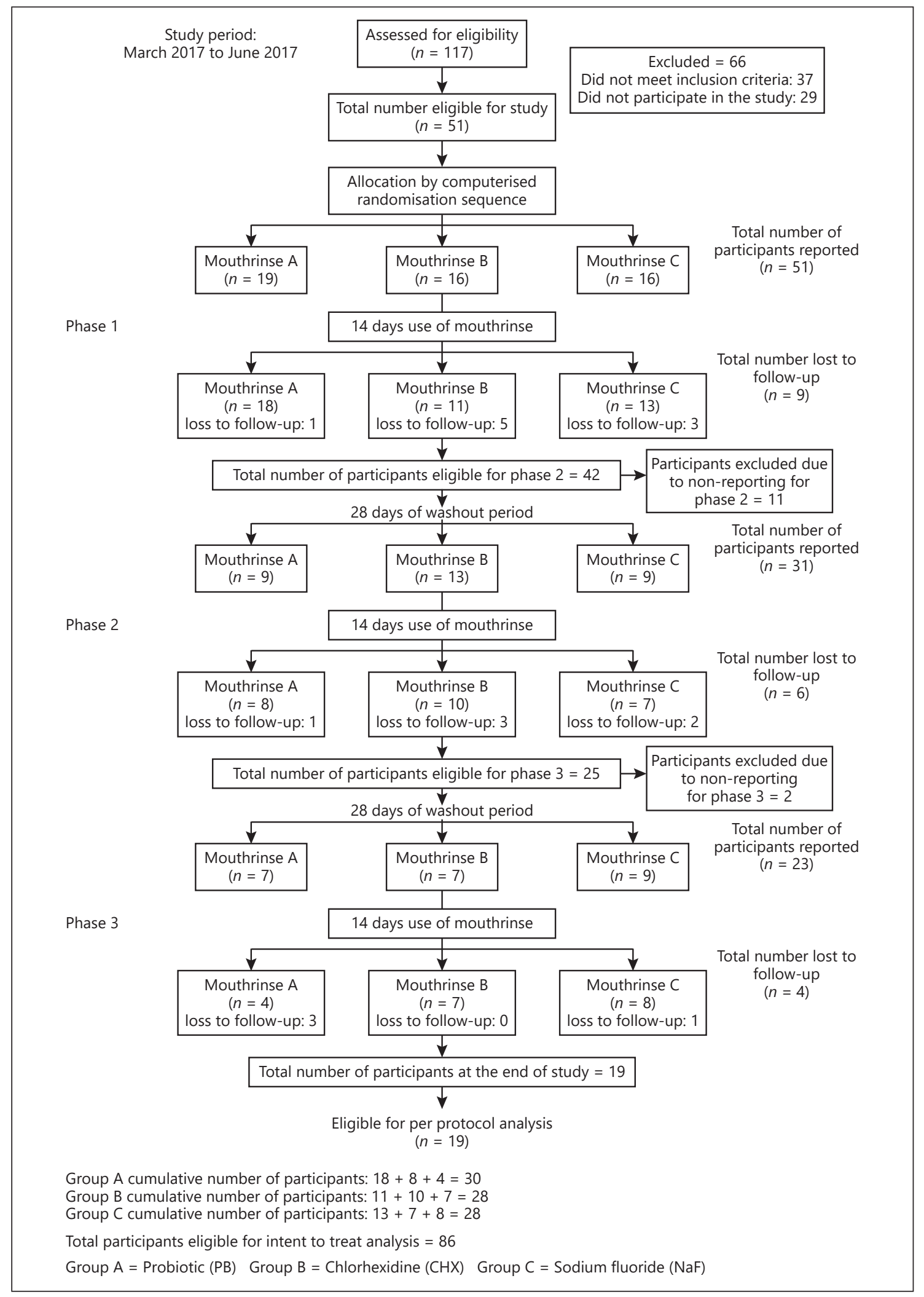

Fig. 1. Flow chart depicting participant allocation, randomization, washout period, follow-up phases, and subsequent attrition in the sample. 
Table 2. Mean change in colony counts of $\mathrm{MS}$ in $\mathrm{CFU} / \mathrm{mL}$ within $\mathrm{PB}, \mathrm{CHX}$, and $\mathrm{NaF}$ mouthrinse groups

\begin{tabular}{lllllll}
\hline Mouthrinse group & \multicolumn{2}{l}{ MS colony counts, mean $\pm \mathrm{SD}^{*}$} & & \multicolumn{1}{l}{$\begin{array}{l}\text { Mean change in colony counts } \\
(95 \% \mathrm{Cl})\end{array}$} & $t$ & $p$ value \\
\cline { 2 - 3 } & baseline & post-interventional & & & \\
\hline $\mathrm{PB}(30)$ & $2.625 \pm 0.7725$ & $1.6027 \pm 0.5670$ & & $-1.0223(-1.2201$ to -0.8246$)$ & -10.574 & $<0.0001$ \\
$\mathrm{CHX}(28)$ & $2.4757 \pm 0.8654$ & $1.5193 \pm 0.7376$ & & $-0.9564(-1.1503$ to -0.7626$)$ & -10.122 & $<0.0001$ \\
$\mathrm{NaF}(28)$ & $2.5021 \pm 0.6589$ & $1.5511 \pm 0.4391$ & & $-0.9511(-1.1554$ to -0.7467$)$ & -9.549 & $<0.0001$ \\
\hline
\end{tabular}

$\mathrm{SD}$, standard deviation; $\mathrm{Cl}$, confidence interval. ${ }^{*} p<0.05$, significant. ${ }^{*} 10^{5} \mathrm{CFU} / \mathrm{mL}$ of the saliva.

Table 3. Mean reduction and mean percentage reduction in colony counts of MS between $\mathrm{PB}, \mathrm{CHX}$, and $\mathrm{NaF}$ mouthrinses considering ITT and PP analysis

\begin{tabular}{|c|c|c|c|c|}
\hline \multirow{2}{*}{$\begin{array}{l}\text { Mouthrinse } \\
\text { group }\end{array}$} & \multicolumn{2}{|l|}{ Mean $\pm S D^{*}$} & \multicolumn{2}{|c|}{ Mean $(\%) \pm S D$} \\
\hline & $\mathrm{ITT}(n=86)$ & $\mathrm{PP}(n=19)$ & $\mathrm{ITT}(n=86)$ & $\mathrm{PP}(n=19)$ \\
\hline PB (30) & $1.0223 \pm 0.5290$ & $1.0037 \pm 0.6006$ & $38 \pm 15$ & $36 \pm 18$ \\
\hline $\mathrm{CHX}(28)$ & $0.9564 \pm 0.5000$ & $1.0637 \pm 0.5195$ & $37 \pm 17$ & $37 \pm 18$ \\
\hline $\mathrm{NaF}(28)$ & $0.9511 \pm 0.5270$ & $0.9037 \pm 0.4807$ & $36 \pm 16$ & $35 \pm 15$ \\
\hline$F$ & 0.171 & 0.432 & 0.081 & 0.062 \\
\hline$p$ value ${ }^{\#}$ & 0.843 & 0.651 & 0.921 & 0.940 \\
\hline
\end{tabular}

SD, standard deviation. ${ }^{\#} p>0.05$, non-significant. $* 10^{5} \mathrm{CFU} / \mathrm{mL}$ of the saliva. groups, was $81 \%$, the individual compliances being $85 \%$ for $\mathrm{PB}, 80 \%$ for $\mathrm{CHX}$ and $77.7 \%$ for NaF, with no statistically significant difference between the three mouthrinses $\left(\chi^{2}=0.343, p>0.05\right)$. Furthermore, we also assessed if any correlation existed between acceptance to taste and compliance to usage; however, the results found no significant association between the two outcomes \{Spearman's coefficient of rank correlation $(\rho)=-0.0724[95 \%$ confidence interval $(-0.290$ to 0.153$)] ; p>0.05\}$.

\section{Effect of Confounding Variables}

An analysis of the confounder variables using ANCOVA suggested that age $(p=0.246)$, sex $(p=0.425)$ and crossover $(p=0.147)$, individually as well as collectively $(p=0.890)$, had no significant effect on the efficacy of the three mouthrinses.

\section{Discussion}

In the last two decades, considerable scientific evidence has been gathered to assert that $\mathrm{PB}$ is beneficial for oral health as a preventive therapy. This form of bacteriotherapy has also been applied for dental caries, as a measure to re-establish a non-cariogenic flora in susceptible individuals. Though the evidence is plenty, it is weak [21]. This study assessed the efficacy of a PB powder in the form of a mouthrinse in children with a high risk of caries. One gram of freeze-dried PB powder is consumed by mixing in $10 \mathrm{~mL}$ of water, as prescribed by general medical practitioners and paediatricians for gut health, and the same has previously been assessed as a mouthrinse in children [17].

Mouthrinses are an ideal vehicle to incorporate chemicals and are appreciated for their ease of use, plaque reduction, and breath-freshening effect [22]. Previous reports have shown that MS is highly susceptible to CHX $[23,24] . \mathrm{NaF}(0.05 \%)$ is the most commonly prescribed mouthrinse in children, and its regular use has shown a reduction in caries increment in permanent teeth [12]. However, $\mathrm{CHX}$ and $\mathrm{NaF}$ mouthrinses have exhibited undesirable adverse effects, which include staining of teeth by $\mathrm{CHX}$, questionable fluorosis by $\mathrm{NaF}$, and allergic reactions. Additionally, the emerging resistance of bacteria to antimicrobial agents cannot be ignored [25]. Synthetic antimicrobial agents kill an array of bacteria, and this can falter the ecology of the oral microbiome. "Bacteriotherapy" in the form of PB can maintain a healthy microbiota and prevent pathogenesis at the same time [1]; hence, a continuous supply of PB microbes, with an acceptable de- 
Table 4. Mean change and mean percentage reduction in colony counts of MS in CFU/mL with PB, CHX, and NaF mouthrinses with cycle (sequence of drug administration) as the variable considering ITT and PP analysis

\begin{tabular}{|c|c|c|c|c|}
\hline $\begin{array}{l}\text { Mouthrinse } \\
\text { group }\end{array}$ & \multicolumn{2}{|l|}{$\mathrm{ITT}(n=86)(95 \% \mathrm{CI})$} & \multicolumn{2}{|l|}{$\mathrm{PP}(n=19)(95 \% \mathrm{Cl})$} \\
\hline PB & $1.0794(0.8346-1.3243)$ & $40.3682(32.9118-47.8606)$ & $1.2200(0.8329-1.6071)$ & $40.6267(28.6254-52.6281)$ \\
\hline $\mathrm{CHX}$ & $0.9636(0.6504-1.2768)$ & $37.3831(27.8218-46.9443)$ & $1.0120(0.5224-1.5016)$ & 31.8651 (16.6844-47.0457) \\
\hline $\mathrm{NaF}$ & $1.1562(0.8681-1.4442)$ & $43.0557(34.2606-51.8508)$ & $1.1500(0.7031-1.5969)$ & $43.1682(29.3102-57.0262)$ \\
\hline$p$ value $\#$ & 0.605 & 0.348 & 0.756 & 0.328 \\
\hline
\end{tabular}

$\mathrm{Cl}$, confidence interval. ${ }^{\#} p>0.05$, non-significant. ${ }^{*} 10^{5} \mathrm{CFU} / \mathrm{mL}$ of the saliva.

livery route, is necessary for optimal effectiveness [26, 27]. Darolac ${ }^{\mathrm{TM}} \mathrm{PB}$ powder (M/s Aristo Pharmaceuticals Pvt. Ltd., Mumbai, India) is a $1 \mathrm{~g}$ freeze-dried powder with not $<1.25$ billion live cells of Lactobacillus rhamnosus, Lactobacillus acidophilus, Bifidobacterium longum, and Saccharomyces boulardii. This PB mouthrinse is a blend of Lactobacilli and Bifidobacterium, which are commensal bacteria and also most recommended for human use due to its adhesion capacity, ability to co-aggregate and colonize on the oral surface [28]. At least $10^{6}-10^{7}$ live $\mathrm{PB}$ per gram or $\mathrm{mL}$ of product are necessary, at the time of its consumption to benefit human health [29].

The three mouthrinses evaluated in this study have unique anti-cariogenic actions against MS. The $0.12 \%$ $\mathrm{CHX}$ gluconate mouthrinse contains hydrosoluble active ingredients that bind to the negatively charged bacterial cell wall, especially to that of Gram-positive MS [30]. NaF, in addition to remineralization of tooth structure, has biological effects against bacteria through inhibition of cellular enzymes by increased permeability of hydrogen fluoride protons that interrupt with the intracellular glycolysis of $S$. mutans to reduce its acid tolerance and acid production [31]. PB mouthrinses act by means of "defence by diversity" [14] and are known to influence levels of MS in saliva [32].

Our results suggest that the $\mathrm{PB}$ mouthrinse proved to be equally efficacious as compared to $\mathrm{CHX}$ and $\mathrm{NaF}$ mouthrinses against MS in 8- to 12-year-old children. Hence, the study fails to reject non-inferiority. To the best of our knowledge, this is the first triple-blinded, threephased, crossover randomized controlled trial reporting on the efficacy of $\mathrm{PB}, \mathrm{CHX}$, and $\mathrm{NaF}$ mouthrinses in 8- to 12 -year-old children. We chose to perform triple-blinding to reduce assessment bias, increase accuracy, and ob- jectivity of results [33]. A crossover design was chosen to reduce subject variability at baseline so that they act as their own control and a "within subject" comparison of treatments promotes internal validity of results [34]. We chose the age group of 8 to 12 years as children of a younger age group might inadvertently swallow liquids, leading to adverse outcomes [35]. Healthy children with a caries score between four and ten were included as the AAPD recommends the use of mouthrinses for children with a high caries risk [36]. Children with an ongoing or recent history of antibiotics were excluded as it influences oral microbial diversity which could have altered clinical outcomes [37]. To re-establish the oral microbiota at baseline before each phase, a washout period of four weeks was provided [18]. Despite stringency in follow-up and planning, there was considerable attrition for which ITT and PP analyses were considered.

PB (labelled as A), 0.12\% CHX (labelled as B) (PerioG$\operatorname{ard}^{\mathrm{TM}}, \mathrm{M} / \mathrm{s}$ Colgate-Palmolive Pvt. Ltd., Mumbai, India), and $0.05 \% \mathrm{NaF}$ (labelled as C) (Fluoritop ${ }^{\mathrm{TM}}, \mathrm{M} / \mathrm{s}$ ICPA Health Products Ltd, Mumbai, India) were dispensed by an independent observer. Before each phase, participants reported for collection of respective mouthrinses and were instructed about its preparation, direction of use, and on their objective role as a participant. Mid-morning paraffin-stimulated salivary samples were collected to minimize effects of the circadian rhythm [20]. Dental treatments of participants were performed in the washout period only as discontinuation for the sake of the trial would have been unethical. Treatments, in addition to crossover, could influence the regrowth of oral microbiota. However, our results suggest that despite cyclic administration of interventions, the baseline counts were re-established in the washout period and had no effect on
Gedam/Katre 
the overall resultant change in colony counts. We additionally considered the difference in mean percentage change instead of assessing absolute change in colony counts to compensate for this possible alteration.

The results of this trial are in accordance with a previous study in adults using similar interventions, with no significant difference in the extent of their effectiveness against MS [19]. Equivalent reductions have also been reported by Ghasempour et al. [18] and Patil et al. [38]. Jindal et al. [17] compared two PB powders as a mouthrinse with a placebo mouthrinse, in 7-14-year-old children and found significant reduction in the salivary MS counts. However, in the study by Kulkarni and Damle [39], CHX was more effective against MS compared to $\mathrm{NaF}$, which is in contradiction to our findings. Aminabadi et al. [30] have shown that CHX used prophylactically before $\mathrm{PB}$ can strengthen the survival of PB bacteria Lactobacillus rhamnosus $G G$ in the oral cavity. PB introduced through different vehicles of administration have been tested in a similar age group. One-week consumption of $\mathrm{PB}$ in the form of curd and ice cream showed reduced MS levels at $1 \mathrm{~h} \mathrm{[40]} \mathrm{and} \mathrm{on} \mathrm{the} \mathrm{7th} \mathrm{day} \mathrm{[40,} \mathrm{41].} \mathrm{Reduction}$ has been reported to last up to a month $[41,42]$, while at 6 months, normal levels of MS were re-established [41]. Hence, long-term effectiveness of $\mathrm{PB}$ is questionable.

Numerous health-beneficial bacteria are being tested to reduce virulence of cariogenic bacteria. Bacillus coagulans Unique IS2 (2 billion CFU) through chewable tablets reduced levels of MS and Lactobacilli in saliva and plaque after two weeks, in 5-15-year-old children [43]. PB ice cream containing Bifidobacterium lactis Bb12 and Lactobacillus acidophilus La5 reduced MS, but levels of oral Lactobacilli remained unaffected [44]. Lactobacilli counts have also remained unaffected after long-term use of a fluoride mouthrinse in contrast to reduced MS levels in children $[45,46]$. Lactobacilli have been known to inhibit the growth and development of S. mutans and overall biofilm formation, which might explain results of aforementioned studies [30].

The taste perception of a paediatric formulation is an important factor to determine patient compliance [47]. To analyse the taste acceptance, we used a Likert rating scale as it is a pre-validated, psychometric scale, commonly used for examining self-reported perceptions and attitudes. It has also been used for assessment of children's feelings, beliefs, and attitudes [48]. The results for taste showed that the PB mouthrinse was "most accepted" for its taste, while all three interventions were ranked "good." Flavouring agents added to mask the original taste of the active ingredient can influence the ranking
[49]. However, individual taste preferences need to be considered while interpreting the results. Compliance was assessed through self-reported calendar markings. Most participants of the study were well-compliant to the three mouthrinses.

Age and sex did not influence the change in colony counts. S. mutans have not been known to have any specific predilection for age or sex in children [50]. No adverse effects were reported by the participants in this trial, possibly due to usage for only two weeks. Parents were advised to supervise the participants while mouthrinsing to prevent inadvertent swallowing. Contact numbers of both investigators were provided to the parents to report emergencies. Even as participants dropped out, no reasons related to side effects were reported when contacted.

Darolac $^{\mathrm{TM}}$ is one of the most commonly prescribed $\mathrm{PB}$ by general practitioners for improvement of gut health [51]. It is easily available and cost-effective (1 sachet is $\sim 10-11$ INR), therefore economical to purchase. Assessment of an inexpensive product with two-way benefits against commercially prominent and costlier products adds to the cost-benefit ratio of the mouthrinses chosen in this trial, and this will specifically benefit population of low socio-economic status. Developing countries like India fail to put strenuous efforts in the implementation of community-level prevention programmes for oral health, and consequently, treatment-based approaches gain focus [17]. The best cost-effective community-level prevention for children would be a school-based intervention in high-risk areas, with $\mathrm{PB}$ powder suspended in milk or water, distributed and monitored by school staff [14], or similar to fluoride recommendation for children, annual exposure to calibrated doses of PB in acceptable vehicles can be administered to children based on their caries risk. This might frequently replenish the oral microbiota with consistency and reduce the caries susceptibility. Researching cost-effective and easily available products for oral health can aid in large-scale prevention programmes and in future, formulate preventive guidelines for public health [17].

The results of this trial may be generalizable to children of a similar age group in similar settings. Future trials with different study designs, settings, and ethnic population groups may yield interesting results, depending upon the strain-specific action of PB [29].

\section{Limitations}

Complete blinding (of the participants) could not be achieved as $\mathrm{PB}$ was available in powder form and hence was dispensed as sachets. Additionally, $\mathrm{CHX}$ and $\mathrm{NaF}$ 
mouthrinses also have unique colours, blue and orange, respectively, which are visible after one begins usage. Individual caries activity of the participants was not assessed. Both streaking of saliva samples and colony counting were performed by the primary investigator. Though this standardized the process of culturing, the effects of intra-examiner variability on the colony counting procedure cannot be overlooked. Participants in our trial were instructed to spit the PB mouthrinse, so any effect on the gut microbiota could not be understood.

The Indian market for $\mathrm{PB}$ has improved in the past decade; however, ready-to-use preparations are not easily available. Most products are available in a capsule form; syrup preparations have the disadvantage of having added sugar which can contribute to decay. Till date, the products follow an old nomenclature to label PB preparations [52]. One study has found that the most commonly available drug is Darolac [51] and can reflect the state of availability of different preparations in most urban metro cities in India.

The present trial suffered more than the estimated attrition as only 19 of the 51 participants completed the study. We observed that maximum participants were lost after the first phase and first washout period (39.22\% loss), while the consecutive phases and washout period had lesser dropouts (Fig. 1). The attrition in this trial was highly influenced by the study period. This trial was planned between the months of March to June, which in India, coincides with school final examination, followed by a long vacation period of approximately two months. This time of the year, residents widely leave for a visit to native places, and a very large number of participants were lost due to this reason. We failed to foresee that this could crucially affect the trial. Additionally, reasons for non-compliance specifically in the first phase could have been related to participation by transiently motivated parents and children, who withdrew when no visible effects were seen after first usage. For this, individual motivation, counselling and oral health awareness may play a key role in compliance. Individuals with a high risk for disease are known to indulge in high-risk behaviours, non-compliance, and laxity in follow-ups [53]. This factor was beyond the control of the investigators. The attrition rate shows that non-adherence to a trial conducted with children can be influenced by factors such as academic schedules, seasonal diseases, and quality of life [54]. Crossover studies are generally prone to attrition as it demands high compliance from participants, wherein a $5-10 \%$ dropout rate can extend up to 25\% [55]. Future crossover studies must take into consideration the challenges developed in this trial and factors that may influence dropouts, especially when recruiting children.

There exists a statistically significant association between reduction in the counts of MS and use of a gutbeneficial PB bacterial therapeutic agent. Within limitations and based on the results of this trial, we may conclude that $\mathrm{PB}$ is as effective as $\mathrm{CHX}$ and $\mathrm{NaF}$ mouthrinses; however, further studies are needed to confirm this claim. PB may be considered as an alternative bacteriotherapeutic regimen effective as a preventive measure in children with moderate to high risk of caries. Future trials can take into consideration any dual beneficial or adverse effects of $\mathrm{PB}$ on the gut microbiome and calibrate the dosage that can benefit both oral and gut health. Cost-to-benefit analysis of PB to other commonly marketed antimicrobial drugs may highlight its effect on economic expenditure needed for prevention to recommend at a community level.

\section{Acknowledgments}

The authors acknowledge the contribution of Dr. Deepak Langade for the statistical analysis, Dr. Jagruti Thakur for assisting in blinding the interventions, Mrs Saylee Pokharkar from Depatment of Oral Pathology and Microbiology for providing laboratory support and Department of Microbiology at Ramnarain Ruia Autonomous College, Mumbai for their co-operation.

\section{Statement of Ethics}

The trial was conducted in accordance with the Declaration of Helsinki and was approved by the Institutional Ethics Committee at YMT Dental College and Hospital (YMTDC\&H/IEC/2015/112). Information sheets were provided to the parents, and a written consent was obtained from the parents before commencement of trial following which an assent was taken from children. This trial is registered with the UMIN-CTR Trial Registry (UMIN ID: UMIN000042958).

\section{Conflict of Interest Statement}

The authors have no conflicts of interest to declare.

\section{Funding Sources}

The trial received no funding from any organization or institute.
Gedam/Katre 


\section{Author Contributions}

A.N.K, K.Y.G: research proposal, theoretical formulations, data analysis, interpretation, manuscript draft. A.N.K: blinding, supervision. K.Y.G: participant recruitment, data collection, literature review. A.N.K, K.Y.G: final manuscript and critical evaluation for intellectual content. Authors are accountable for all aspects of the research conducted.

\section{Data Availability Statement}

All data generated through this trial has been included in this paper. Any further enquiries are to be directed to the corresponding author.

\section{References}

1 Zarco MF, Vess TJ, Ginsburg GS. The oral microbiome in health and disease and the potential impact on personalized dental medicine. Oral Dis. 2012 Mar;18(2):109-20.

2 Shanmugam K, Sarveswari HB, Udayashankar A, Swamy SS, Pudipeddi A, Shanmugam $\mathrm{T}$, et al. Guardian genes ensuring subsistence of oral Streptococcus mutans. Crit Rev Microbiol. 2020 Aug;46(4):475-91.

3 Clarke JK. On the bacterial factor in the ætiology of dental caries. Br J Exp Pathol. 1924 Jun; 5(3):141-7.

4 Tanner AC, Kressirer CA, Faller LL. Understanding caries from the oral microbiome perspective. J Calif Dent Assoc. 2016 Jul; 44(7):437-46.

5 Petersen PE, Bourgeois D, Ogawa H, Estupinan-Day S, Ndiaye C. The global burden of oral diseases and risks to oral health. Bull World Health Organ. 2005 Sep;83(9):661-9.

6 Bali RK, Mathur VB, Talwar PP, Chanana HB. National oral health survey and fluoride mapping 2002-2003 India. New Delhi: Dental Council of India; 2004. p. 132.

7 Marsh PD. Ecological events in oral health and disease: new opportunities for prevention and disease control? J Cal Dent Assoc. 2017 Oct;45(10):525-37.

8 Abdul Razak I. Toothbrushing effectiveness of a group of six-year-old uninstructed school children. Dent J Malays. 1985 Apr;8(2):2730.

9 Wakamatsu R, Takenaka S, Ohsumi T, Terao Y, Ohshima H, Okiji T. Penetration kinetics of four mouthrinses into Streptococcus mutans biofilms analyzed by direct time-lapse visualization. Clin Oral Investig. 2014 May; 18(2):625-34.

10 Ohsumi T, Takenaka S, Sakaue Y, Suzuki Y, Nagata R, Hasegawa T, et al. Adjunct use of mouth rinses with a sonic toothbrush accelerates the detachment of a Streptococcus mutans biofilm: an in vitro study. BMC Oral Health. 2020 Jun 3;20(1):161.

11 Jones CG. Chlorhexidine: is it still the gold standard? Periodontol 2000. 1997 Oct;15:5562.

12 Marinho VC, Chong LY, Worthington HV Walsh T. Fluoride mouthrinses for preventing dental caries in children and adolescents. Cochrane Database Syst Rev. 2016 Jul 29;7(7): CD002284.

Efficacy of a Probiotic Mouthrinse on Mutans Streptococci
13 Hill C, Guarner F, Reid G, Gibson GR, Merenstein DJ, Pot B, et al. The International Scientific Association for Probiotics and Prebiotics consensus statement on the scope and appropriate use of the term probiotic. Nat Rev Gastroenterol Hepatol. 2014 Jun;11:506-14.

14 Zaura E, Twetman S. Critical appraisal of oral pre- and probiotics for caries prevention and care. Caries Res. 2019;53(5):514-26.

15 Zare Javid A, Amerian E, Basir L, Ekrami A, Haghighizadeh MH, Maghsoumi-Norouzabad L. Effects of the consumption of probiotic yogurt containing bifidobacterium lactis Bb12 on the levels of Streptococcus mutans and Lactobacilli in saliva of students with initial stages of dental caries: a double-blind randomized controlled trial. Caries Res. 2020 Dec;54(1):68-74.

16 Stecksén-Blicks C, Sjöström I, Twetman S. Effect of long-term consumption of milk supplemented with probiotic lactobacilli and fluoride on dental caries and general health in preschool children: a cluster-randomized study. Caries Res. 2009 Oct;43(5):374-81.

17 Jindal G, Pandey RK, Agarwal J, Singh M. A comparative evaluation of probiotics on salivary mutans streptococci counts in Indian children. Eur Arch Paediatr Dent. 2011 Aug. 12(4):211-5.

18 Ghasempour M, Sefdgar SA, Moghadamnia AA, Ghadimi R, Gharekhani S, Shirkhani L. Comparative study of Kefir yogurt-drink and sodium fluoride mouth rinse on salivary mutans streptococci. J Contemp Dent Pract. 2014 Mar;15(2):214-7.

19 Jothika M, Vanajassun PP, Someshwar B. Effectiveness of probiotic, chlorhexidine and fluoride mouthwash against Streptococcus mutans - randomized, single-blind, in vivo study. J Int Soc Prev Community Dent. 2015 May;5(Suppl 1):S44-8.

20 Dawes C. Circadian rhythms in human salivary flow rate and composition. J Physiol. 1972 Feb;220(3):529-45.

21 Gruner D, Paris S, Schwendicke F. Probiotics for managing caries and periodontitis: systematic review and meta-analysis. J Dent. 2016 May;48:16-25.

22 Van der Weijden FA, Van der Sluijs E, Ciancio SG, Slot DE. Can chemical mouthwash agents achieve plaque/gingivitis control? Dent Clin North Am. 2015 Oct;59(4):799829.
23 Emilson CG. Potential efficacy of chlorhexidine against mutans streptococci and human dental caries. J Dent Res. 1994 Mar;73(3): 682-91.

24 Coelho ASEC, Paula ABP, Carrilho TMP, da Silva MJRF, Botelho MFRR, Carrilho EVVF. Chlorhexidine mouthwash as an anticaries agent: a systematic review. Quintessence Int. 2017 Jul;48(7):585-91.

25 Balasubramanian AR, Vasudevan S, Shanmugam K, Lévesque CM, Solomon AP, Neelakan$\tan$ P. Combinatorial effects of trans-cinnamaldehyde with fluoride and chlorhexidine on Streptococcus mutans. J Appl Microbiol. 2021 Feb;130(2):382-93.

26 Twetman S, Jørgensen MR, Keller MK. Fifteen years of probiotic therapy in the dental context: what has been achieved? J Calif Dent Assoc. 2017 Oct;45(10):539-45.

27 Schnack ME. The oral microbiome, dental caries and probiotics. 2019. In Creative Components.245. Available from: https://lib. dr.iastate.edu/creativecomponents/245.

28 Nadelman P, Magno MB, da Cruz MF, da Cruz AG, Pithon MM, Fonseca-Gonçalves A, et al. Chapter 12, the effect of probiotics on oral health. In: Chauhan DN, Singh PR, Shah K, Singh Chauhan N, editors. Natural oral care in dental therapy. Hoboken, New Jersey: Wiley-Scrivener Publishing LLC; 2020. p. 171-95.

29 Bustamante M, Oomah BD, Mosi-Roa Y, Rubilar M, Burgos-Díaz C. Probiotics as an adjunct therapy for the treatment of halitosis, dental caries and periodontitis. Probiotics Antimicrob Proteins. 2020 Jun;12(2):325-34.

30 Aminabadi NA, Erfanparast L, Ebrahimi A, Oskouei SG. Effect of chlorhexidine pretreatment on the stability of salivary lactobacilli probiotic in six- to twelve-year-old children: a randomized controlled trial. Caries Res. 2011 May;45(2):148-54.

31 Buzalaf MAR, Pessan JP, Honório HM, Ten Cate JM. Mechanisms of action of fluoride for caries control. Monogr Oral Sci. 2011;22:97114

32 Arweiler NB, Auschill TM, Heumann C, Hellwig $\mathrm{E}, \mathrm{Al}$-Ahmad A. Influence of probiotics on the salivary microflora oral streptococci and their integration into oral biofilm. Antibiotics. 2020 Nov 13;9(11):803. 
33 Salkind NJ, editor. Encyclopedia of research design. Thousand Oaks, CA: SAGE Publications, Inc.; 2010.

34 Sedgwick P. What is a crossover trial? BMJ. 2014 May 9;348:g3191.

35 Mariotti AJ, Burrell KH. Mouthrinses and dentifrices. ADA/PDR guide to dental therapeutics. 5th ed. Chicago, IL: American Dental Association; 2009. p. 305-22.

36 American Academy of Pediatric Dentistry. Periodicity of examination, preventive dental services, anticipatory guidance/counseling, and oral treatment for infants, children, and adolescents. The reference manual of pediatric dentistry. Chicago, IL: American Academy of Pediatric Dentistry; 2020. p. 232-42.

37 Ready D, Lancaster H, Qureshi F, Bedi R, Mullany P, Wilson M. Effect of amoxicillin use on oral microbiota in young children. Antimicrob Agents Chemother. 2004 Aug;48(8): 2883-7.

38 Patil RU, Dastoor PP, Unde MP. Comparative evaluation of antimicrobial effectiveness of probiotic milk and fluoride mouthrinse on salivary Streptococcus mutans counts and plaque scores in children: an in vivo experimental study. J Indian Soc Pedod Prev Dent. 2019 Oct-Dec;37(4):378-82.

39 Kulkarni VV, Damle SG. Comparative evaluation of efficacy of sodium fluoride, chlorhexidine and triclosan mouth rinses in reducing the mutans streptococci count in saliva: an in vivo study. J Indian Soc Pedod Prev Dent. 2003 Sep;21(3):98-104.

40 Bhalla M, Ingle NA, Kaur N, Yadav P. Mutans streptococci estimation in saliva before and after consumption of probiotic curd among school children. J Int Soc Prev Community Dent. 2015 Jan-Feb;5(1):31-4.
41 Ashwin D, Ke V, Taranath M, Ramagoni NK, Nara A, Sarpangala M. Effect of probiotic containing ice-cream on salivary mutans streptococci (SMS) levels in children of 6-12 years of age: a randomized controlled double blind study with six-months follow up. J Clin Diagn Res. 2015 Feb;9(2):ZC06-9.

42 Juneja A, Kakade A. Evaluating the effect of probiotic containing milk on salivary mutans streptococci levels. J Clin Pediatr Dent. 2012; 37(1):9-14.

43 RatnaSudha M, Neelamraju J, Surendra Reddy M, Kumar M. Evaluation of the effect of probiotic Bacillus coagulans unique IS2 on mutans streptococci and lactobacilli levels in saliva and plaque: a double-blind, randomized, placebo-controlled study in children. Int J Dent. 2020 Dec;2020:8891708.

44 Singh RP, Damle SG, Chawla A. Salivary mutans streptococci and lactobacilli modulations in young children on consumption of probiotic ice-cream containing Bifidobacterium lactis Bb12 and Lactobacillus acidophilus La5. Acta Odontol Scand. 2011 Nov;69(6):389-94.

45 Yoshihara A, Sakuma S, Kobayashi S, Miyazaki H. Antimicrobial effect of fluoride mouthrinse on mutans streptococci and lactobacilli in saliva. Pediatr Dent. 2001 Mar-Apr;23(2): 113-7.

46 Kaneko N, Yoshihara A, Ida H, Nomura Y, Imai S, Nisizawa T, et al. Influence of a fluoride mouthrinse on mutans streptococci in school children. Caries Res. 2006 Oct;40(6): 501-7.
47 Bagger-Sjöbäck D, Bondesson G. Taste evaluation and compliance of two paediatric formulations of phenoxymethylpenicillin in children. Scand J Prim Health Care. 1989 Jun; 7(2):87-92.

48 Mellor D, Moore KA. The use of Likert scales with children. J Pediatr Psychol. 2014 Apr; 39(3):369-79.

49 Storehagen S, Ose N, Midha S. Dentifrices and mouthwashes ingredients and their use. 2003:7. Available from: https://www.duo.uio. no/bitstream/handle/10852/33076/Storehagen_Ose_Midha.pdf.

50 Mitrakul K, Asvanund Y, Vongsavan K. Prevalence of five biofilm-related oral streptococci species from plaque. J Clin Pediatr Dent. 2011;36(2):161-6.

51 Sehgal S, Dhewa T, Bansal N, Thakur M. Probiotic drugs and labeling practices in Indian market. Delhi Univ J Undergrad Res Innov. 2016 Oct;2(1):166-70.

52 Ghattargi VC, Kalam SH, Pandit SS, Pawar SP, Shouche YS. Survey of probiotic preparations and labeling practices in Indian market. Indian J Med Microbiol. 2018 Jan-Mar;36: 116-8.

53 Pellmar TC, Brandt EN Jr, Baird MA. Health and behavior: the interplay of biological, behavioral, and social influences: summary of an Institute of Medicine report. Am J Health Promot. 2002 Mar-Apr;16(4):206-19.

54 Bell ML, Kenward MG, Fairclough DL, Horton NJ. Differential dropout and bias in randomised controlled trials: when it matters and when it may not. BMJ. 2013 Jan 21;346:e8668.

55 Godolphin PJ, Godolphin EJ. Robustness of crossover trials against subject drop-out - examples of perpetually connected designs. Stat Methods Med Res. 2019 Mar;28(3):788-800. 